gives agreement to better than one unit. One particle has been found with $Z=30$.

Mrs. R. Gall, of the Institute of Geophysics, University of Mexico, gave an account of the work carried out there by the theoretical group on the trapping of charged particles in the geomagnetic field and on the relation between the radiation belts and the inner allowed region of Störmer. Work is also being carried out on the motion of cosmic ray albedo particles in Earth's field and on the changes in threshold momenta resulting from the secular variation in the geomagnetic field. At some points on Earth's surface these changes have amounted to as much as 25 per cent during the past hundred years.

This course, which is a biennial event, provides, in addition to the presentation of original work and review lectures, a forum for the discussion and co-ordination of future programmes in cosmic-ray research in the participant countries. The two previous courses were held in La Paz, Bolivia, and San Carlos de Bariloche, Argentina, and it is intended that the next one should be held once again in Bolivia. In a report of this length it has only been possible to select a few representative aspects of the work reported by the Latin-American groups.

H. ELLIOT

\title{
PHARMACEUTICAL CONTROL IN BRITAIN
}

$I^{\mathrm{N}}$ $\mathrm{N}$ his chairman's address to the British Pharmaceutical Conference, held at Portsmouth during September 18-22, Dr. D. C. Garratt states a case for a more effective control of the quality of medicinal substanees. Drugs not governed by official standards should not become available to the public except under a notification scheme, similar to that already in force for pesticides, so that their clinical characters and standards of purity, with appropriate methods of analysis, would have prior approval. Standards for all medicines should be enforeed by testing in regional laboratories specialized for the purpose and maintained by the Ministry of Health. For reputable approved firms, the contractor's own inspection organization could be given the initial responsibility for compliance of goods with specification. The pharmaceutical analysis involved should be admitted as a distinct discipline, by the institution of special training courses and recognized qualifications.

At present, control analysis is too often rendered pointless by insufficient attention to the precision of the methods involved; and for a full realization of the potentialities of such techniques as, for example, ultra-violet spectrophotometry, a national collection of standard specimens of authentic materials of known impurity content is essential. Authority for the enforcement of those standards should be incorporated in an Act of Parliament.

It should be every analyst's concern to consider what can be done to reduce costs of examinations, for example, by using equally effective, but cheaper, solvents, by applying rapid instrumental techniques or, where possible, by replacing costly bio-assay investigations by simpler paper chromatographic techniques.

Dr. Garrett suggests that the public would receive better protection if the control of drugs were divorced from the present Food and Drugs Act and incorporated in a new Medical Substances and Preparations Act built around Sections 11, 12 and 13 of the Pharmacy and Medicines Act. Imported drugs should be subject to stringent examination by analysts of acceptable status. Such status might be conditional on the possession of a special diploma incorporated as a requirement of competence in the proposed Medical Substances and Preparations Act. Examinations for such diploma qualifications would be conducted by those chemical or pharmaceutical institutions approved by the Ministry of Health.

\section{THE LABORATORY OF THE GOVERNMENT CHEMIST}

T HE very varied work done in the Laboratory of the Government Chemist during 1960 has recently been reported*. The Laboratory, which forms part of the Department of Scientific and Industrial Research, exists to provide a service to any Government department that requests it on matters broadly concerned with chemistry, and more particularly with chemical analysis. The Laboratory is the oldest Government chemical institution in the Commonwealth. It was created in 1842 by the Board of Inland Revenue, principally to assist the revenue authorities in detecting and preventing the adulteration of tobacco with worthless additives. The special responsibilities which the Laboratory retains to H.M. Customs and Excise are highlighted by the number of samples received from this authority. Of a total of 327,460 samples examined and reported on by the Laboratory during the year, no less than 280,125 were submitted by H.M. Customs and Excise. These samples cover a wide range of dutiable com-

* Department of Scientiffe and Industrial Research: Laboratory of the Government Chemist. Report of the Government Chemist, 1960 Pp. iv + 79. (London: H.M.S.O., 1961.) 5s. net, modities such as wines, beers and spirits, sugar, textiles, fuel oils, etc.

The statutory duties of the Government Chemist under the Food and Drugs Act, the Fertiliser and Feeding Stuffs Act, and the National Health Act, involve the Laboratory in such work as the analysis of orange juice, dried milk, fertilizers, pesticide chemicals and formulations thereof, pharmaceuticals and drugs, canned foods. Examples of the variety of this work are the determination of glycogen in oysters and the iodine content of school dinners.

An organization which exists to provide an advisory service must carry out a considerable number of routine analyses as, for example, on the variety of materials purchased by various Government departments ; this work varies little from year to year.

Important work from the public health point of view concerns the examination of water and sewage. Much attention is given to the control of fluoridation in municipal supplies (where this is practised). The control of micro-organisms in the Serpentine bathing area is an item of special interest to Londoners. 
The Laboratory of the Government Chemist is very often involved in legal cases arising out of such illegalities as the dilution of beer, illicit distilling and forgery. The present report gives some excellent illustrations on the methods used to detect forgeries.

Although mainly concerned with the utilization of existing analytical methods, the Laboratory carries out a considerable amount of research work on the improvement of analytical methods and their adaptation to meet problems peculiar to the types of sample received for analysis. The report also indicates that the small but increasing research programme on the development of new methods of analy- sis is meeting with considerable success. The new radiochemical section has begun work for municipal water supplies, and on the analysis of effluents from atomic energy establishments.

This report shows admirably that as a means for safeguarding the public interest over a wide field of activity, the Laboratory is second to none. This report has been read with considerable interest not only for its scientific content but also for the extreme diversity of its contents. The new Government Chemist, Dr. D. T. Lewis, is to be congratulated on the presentation of this, his first report.

William I. Stephen

\section{AMSTERDAM CONFERENCE ON PARTICLE ACCELERATORS}

\begin{abstract}
7 HE January number of Nuclear Instruments and Methods* is devoted entirely to the proceedings of the Second Accelerator Conference which was held in Amsterdam during October 4-6, 1960. The Conference, which was sponsored by the High Voltage Engineering Corporation, Burlington, Massachusetts, and High Voltage Engineering (Europa) N. V., Amersfoort, The Netherlands, consisted of four sessions, under the chairmanship of Profs. H. Brinkman (University of Groningen), H. H. Staub (University of Zurich), K. Siegbahn (University of Uppsala) and A. Charlesby (Royal Military College of Science), respectively. The seven papers in the first session were devoted to nuclear physics, and dealt with resonance reactions, the generation of positrons in a thick target, desirable linear electron accelerator characteristics for nuclear research, Coulomb excitation, experiments using ultra-fast pulse techniques, nuclear widths and life-times, and colliding beam techniques. Three of the six papers in the session on particle research discussed tandem accelerators. P. H. Rose of the High Voltage Engineering Corporation described two forms of the three-stage tandem accelerator, one with negative ion injection and the other with neutral beam injection. H. E. Gove of the Atomic Energy of Canada, Ltd., gave an account of the tandem accelerator installation at Chalk River and of two particular fields of investigation during 1960. The Chalk River accelerator began operating in February 1959 and has operated continuously on a two-shift a day, five-day week basis since then. The

* Nuclear Instruments and Methods, 11, No. 1: Proceedings of the Second Accelerator Conference, Amsterdam, October 4-6, 1960. Edited by $\mathrm{K}$. Siegbahn. Pp. xil + 256. (Amsterdam: North-Holland Publishing Company). 908 .
\end{abstract}

first investigation was concerned with the interaction between beams of heavy ions such as carbon-12, nitrogen-14 and oxygen-16, with targets of nitrogen, oxygen, fluorine, neon, magnesium, aluminium and silicon, and the second with measurements of spins of levels in even-even nuclei lying between oxygen-16 and calcium-40. Recent research work carried out at the Atomic Weapons Research Establishment, Aldermaston, on nuclear reactions using a tandem accelerator and $6 \cdot \mathrm{MeV}$. electrostatic generators $w$ as described by K. W. Allen. Oxygen ions accelerated in the accelerator to energies of $10-40 \mathrm{MeV}$. were used for Coulomb excitation of energy-levels in both rotational and vibrational nuclei and for the measurement of nuclear life-times by Doppler-shift methods. The final paper in the nuclear physics session was given by J. C. Nygard and R. F. Post on recent advances in high-power micro-wave electron accelerators for physics research.

The third and final sessions were devoted to physics and radiation research. The subjects covered included the use of Van de Graaff accelerators, pulsed neutron sources and ion sources. In the industrial applications section, the use of the electron accelerator in solid-state physics, and of high-energy radiation in biochemical and microbiological research were discussed by P. Baruch, and S. T. H. Pinner and W. T. H. Davison, respectively. The report of the proceedings concludes with a most impressive and long list of accelerators (Van de Graaff, micro-wave linear electron and Cockcroft-Walton) which have been installed in various centres all over the world by the High Voltage Engineering Corporation, and associated companies.

\section{CONTINENTAL AND OCEANIC DIFFERENTIATION}

$\mathrm{D}^{\mathrm{n}}$ R. ROBERT DIETZ'S recent article ${ }^{1}$ is a marked contribution to what might be called the oceanographic revolution in geotectonics. One gets the impression that with it a stage has been reached like the last but one in fitting together a jigsaw puzzle, with the various parts of the puzzle having been laboriously assembled, piece by piece, at last seeming to look as if they are all part of one single picture.

What Dr. Dietz has done, effectively, is to combine the notions derived from the recent discovery of oceanographers of mid-oceanic rift ridges and transcurrent faults, with the older pictures, derived from earthquake and gravity measurements, of the pushing up of continental edges along conical thrust faults exposing themselves as mountain ranges, island-arcs and trench systems, according to the ideas of Meinesz and van Bemmelen, and set out specially by Tuzo Wilson. The leading new idea, linked with the still hypothetical mantle convexion systems, is one of expanding oceanic floors, split vertically by latitudinal and circumoceanic transcurrent faults, passing under the continents. This removes many difficulties and makes it possible to envisage a mantle which can expand under some parts of the crust and contract under others at the same time. 